\title{
MONITORING GROUND DEFORMATION USING PERSISTENT SCATTERS INTERFEROMETRY (PSI) AND SMALL BASELINES (SBAS) TECHNIQUES INTEGRATED IN THE ESA RSS SERVICE: THE CASE STUDY OF VALENCIA, ROME AND SOUTH SARDINIA
}

\author{
J. Manuel Delgado ${ }^{(1,2)}$, Roberto Cuccu ${ }^{(1)}$, Giancarlo Rivolta ${ }^{(1)}$ \\ ${ }^{(1)}$ Progressive Systems Srl, Parco Scientifico di Tor Vergata, 00133 Roma (Italy); \\ e-mails: josemanuel.delgado@progressivesystems.it; roberto.cuccu@progressivesystems.it; \\ giancarlo.rivolta@progressivesystems.it \\ ${ }^{(2)}$ Universidad de Jaén - Grupo de Investigación RNM282 “Microgeodesia Jaén”, Campus Las lagunillas s/n, 23071 \\ Jaén (Spain)
}

\begin{abstract}
This work is focused on the infrastructure monitoring of areas which had experienced significant urbanization and therefore, also an increase of the exploitation of natural resources. Persistent Scatters Interferometry (PS-InSAR) and Small Baselines (SBAS) approaches are applied to three study areas for which large datasets of SAR images are available in ascending and descending modes to finally deploy deformation maps of different buildings and infrastructures. Valencia, Rome and South Sardinia areas have been selected for this study, having experienced an increase of the exploitation of natural resources in parallel with their urban expansion. Moreover, Rome is a very special case, where Cultural Heritage permeating the city and its surroundings would suggest the necessity of a tool for monitoring the stability of the different sites. This work wants to analyse the potential deformation that had occurred in these areas during the period 1992 to 2010, by applying Persistent Scatters Interferometry to ESA ERS SAR and Envisat ASAR data.
\end{abstract}

\section{INTRODUCTION}

This paper aims to demonstrate the capabilities of the services provided by the ESA Research \& Service Support service (RSS) [1].

The main objective of the RSS service mission is to support the Earth Observation (EO) community in the EO data exploitation by providing effective and efficient solutions for data access and processing, algorithm development and integration and massive products generation. The winning proposed model is to bring "users" to "EO Data". One of the provided service that implements the new paradigm is Grid Processing On Demand (G-POD) environment which integrates in a single instance fast data access, scientific algorithms and processing resources.

Within the G-POD environment it is available a suite of inteferometric services that has been used in this work, which includes the following automated and integrated tools: DORIS [2], StaMPS [3] and P-SBAS [4] developed by CNR-IREA.

Another important service that has been exploited in this work is the RSS CloudToolbox Virtual Machine (VM) service which provides an environment with flexible computing capacity and ready-to-use processing software tailored on the user need.

In this study we selected three areas of interest, Valencia, Rome and Cagliari, that had been already studied in the past for testing the robustness and reliability of the integrated services.

The deformation of Rome has been widely analysed using Persistent Scatterers Interferometry (PSI) in the past [5], and the deformation of the historic centre of Rome was analysed more recently using CosmoSkymed data[6].

Valencia has been only studied in the past with DInSAR using few Envisat ASAR and TerraSAR-X interferograms [7]. In this work, we increase the area under study with a larger datasets to be able to apply PSI and analyse the stability of the city and its surroundings.

Finally, Cagliari has been studied in the past, using only ERS SAR datasets [8]. In this paper we performed the analysis using the entire ESA SAR archive from 1995 to 2010

\section{STUDY AREAS AND DATASETS}

The selected study areas are from West to East: (i) Valencia, (ii) Cagliari and (iii) Rome, situated inside the red rectangles in Fig. 1. 


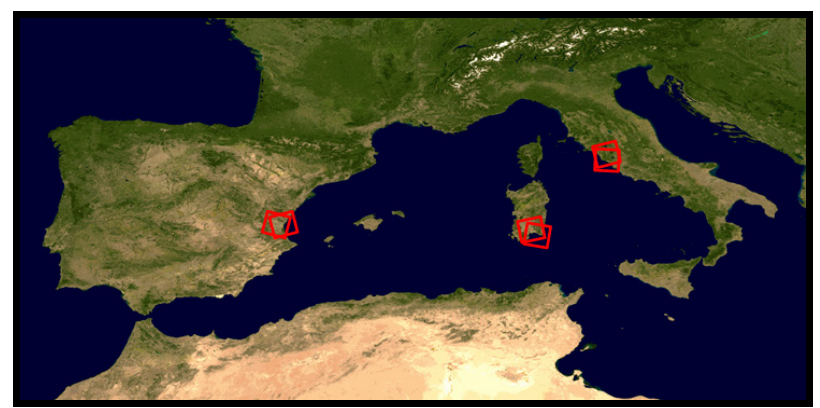

Figure 1. Selected study areas

The selected datasets are directly accessible via G-POD and are indicated in the Table. 1.

Table 1. Datasets employed for the study areas

\begin{tabular}{|l|l|l|r|r|r|}
\hline $\begin{array}{l}\text { Study } \\
\text { area }\end{array}$ & Satellite & $\begin{array}{l}\text { Orbit } \\
\text { Pass }\end{array}$ & Track & $\begin{array}{l}\text { N. } \\
\text { SLCs }\end{array}$ & $\begin{array}{l}\text { N. SLCs } \\
\text { selected }\end{array}$ \\
\hline \multirow{3}{*}{ Valencia } & ERS & desc. & 466 & 35 & 33 \\
& Envisat & asc. & 330 & 26 & 25 \\
& Envisat & desc. & 466 & 35 & 34 \\
\hline \multirow{3}{*}{ Rome } & ERS & desc. & 351 & 52 & 35 \\
& Envisat & asc. & 172 & 51 & 34 \\
& Envisat & desc. & 351 & 39 & 31 \\
\hline \multirow{2}{*}{ Cagliari } & ERS & desc. & 165 & 43 & 35 \\
& Envisat & desc. & 165 & 28 & 21 \\
\hline \multirow{2}{*}{ TOTAL } & & & 8 & 309 & 248 \\
\hline
\end{tabular}

\section{METHODOLOGY}

In this paper we have applied Persistent Scatterers Interferometry (PS-InSAR) for the stability and infrastructure analysis of the mentioned areas in three processing steps. Such processing has been carried out by using the ESA Research and Service Support (ESA RSS) service for each track as follows:

1. The user processed automatically the entire interferogram processing chain using the DORIS [2] services available in the Grid Processing on Demand (G-POD).

Single master interferograms are produced for the entire tracks, selecting as master the best master image based on master-slave Doopler difference, temporal baseline and perpendicular baselines.

After the interferogram generation, only the image pairs with perpendicular baseline lower that the respective critical baseline and with average coherence higher than 0.15 are used in the further processing. The total number of SLCs selected after this step are indicated in the last column in Tab.1.

2. The selected interferograms are transferred to a CloudToolbox Virtual Machine (VM) provided by ESA RSS for PSI processing is performed using StaMPS [3] (Stanford Method for
Persistent Scatterers) software installed on the $\mathrm{VM}$, in order to perform a PSI processing

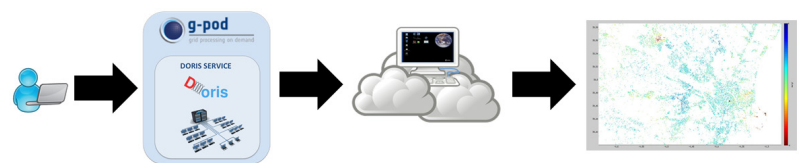

Figure 2. Processing chain using DORIS service in $G-P O D$ and CloudToolbox VM services

3. Results cross-check is performed using another interferometric service available on G-POD, called P-SBAS, offered by CNR-IREA [4].

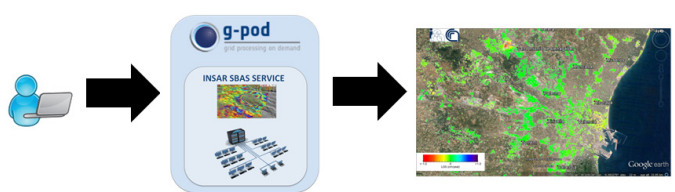

Figure 3. Cross-check processing using CNR-IREA service in $G-P O D$

\section{RESULTS}

\subsection{Valencia}

The results show that two areas inside the city of Valencia had suffered subsidence phenomena: the harbour (zone A) and the North-East part, named Algiros quartier (zone B), both areas visible in Fig.4, 5 and 6.

The Envisat ASAR results, show a new subsidence area over the two towns La Eliana and San Antonio de Benageber (zone C), with high Line-of-Sight (LOS) deformation velocities. This new area of subsidence appears in both ascending and descending tracks, as visible in fig. 5 and 6.

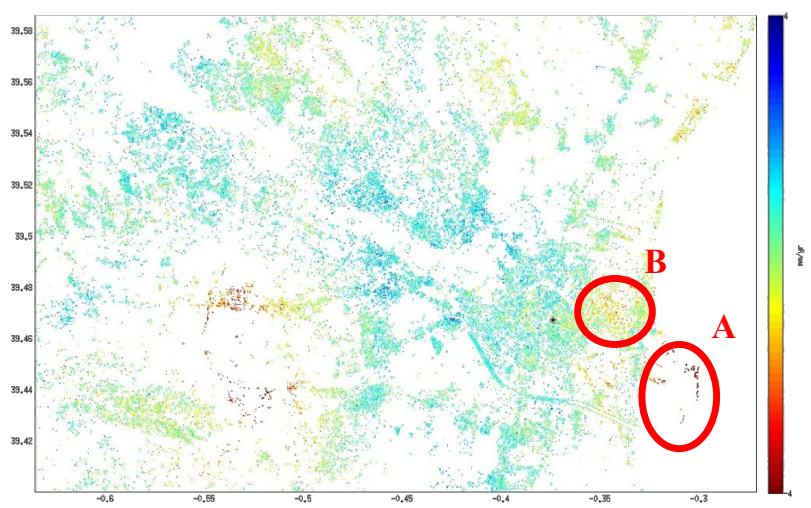

Figure 4. LOS deformation velocities over Valencia area obtained with ERS-1/2 SAR descending track 466 from 1992 to 2000. 


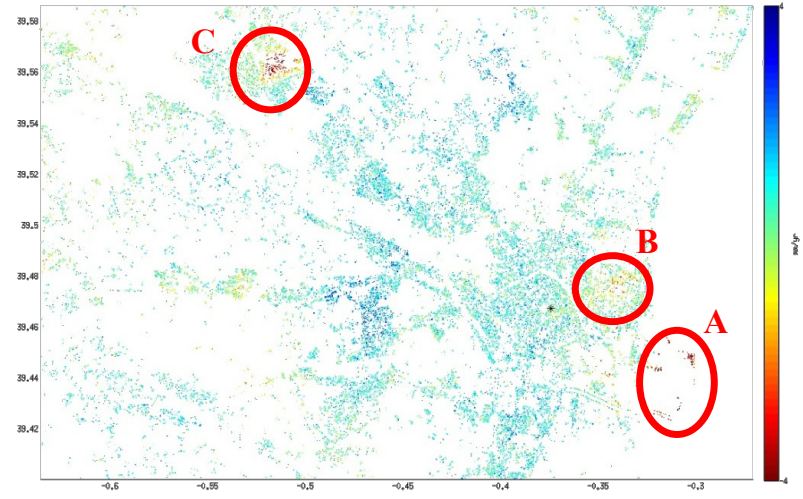

Figure 5. LOS deformation velocities over Valencia area obtained with Envisat ASAR descending track 466 from 2003 to 2010.

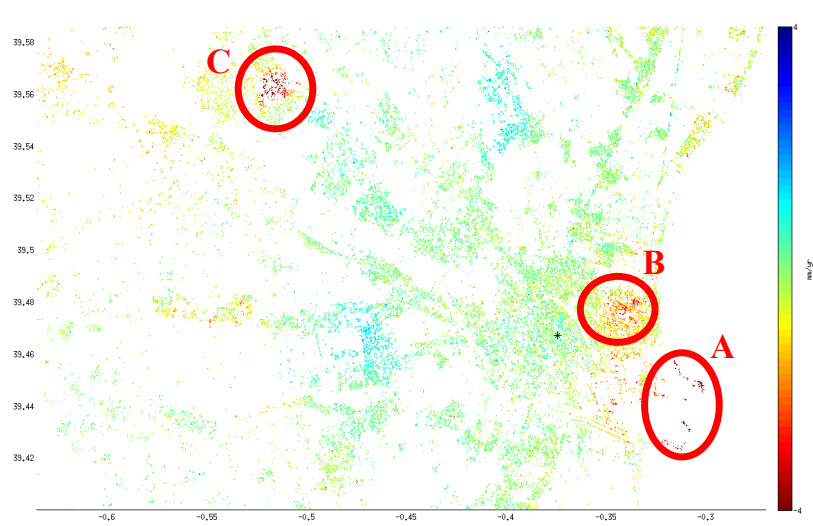

Figure 6. LOS deformation velocities over Valencia area obtained with Envisat ASAR ascending track 330 from 2003 to 2010.

The detailed LOS deformation of a small group of points located in the harbour area for the period 1993 to 2000 is represented in fig. 7, and for the period 2003 to 2010 in fig.8. Both figures show an average deformation near to $50 \mathrm{~mm}$ from 1993 to 2000 and $30 \mathrm{~mm}$ from 2003 to 2010 .

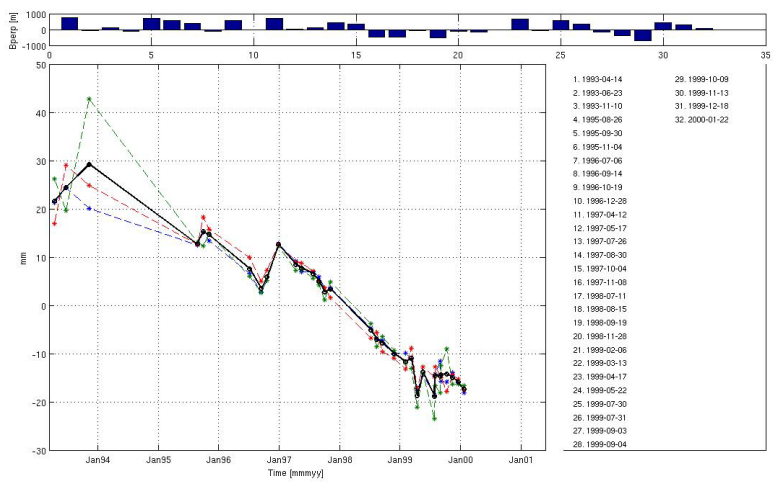

Figure 7. Time series of the harbour area (zone A), showing a subsidence trend from 1992 to 2000.

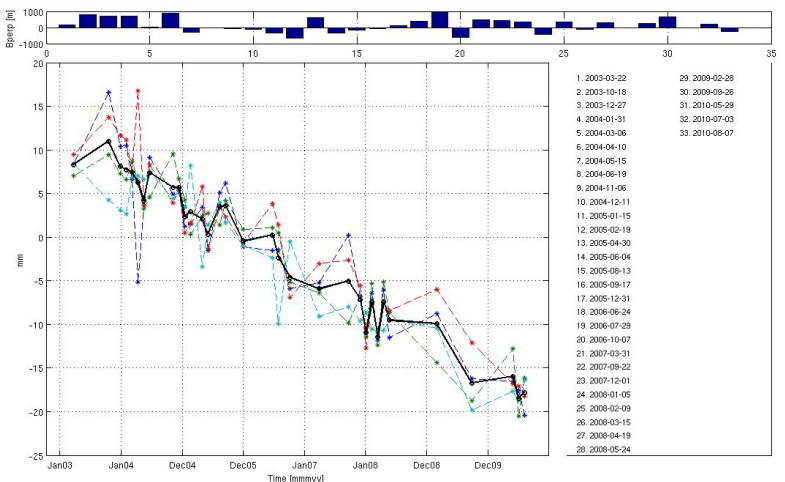

Figure 8. Time series of the harbour area (zone A), showing a subsidence trend from 2003 to 2010.

\subsection{Rome}

The results obtained over Rome reveal several areas of subsidence for the entire period 1992 to 2010. The ones with the highest Line-of-Sight deformation velocities are located: (i) along the Tiber river, as already identified in [2], (ii) Fiumicino airport and surroundings (zone D), as represented in fig. 9, 10 and 11.

The highest LOS deformation rate in zone D is observed in the descending Envisat ASAR results, track 351, being about $7 \mathrm{~mm} /$ year, and the average deformation velocity is about $5 \mathrm{~mm} /$ year.

The detailed deformation for a group of points belonging to a $100 \mathrm{~m}$ radius circle over zone $\mathrm{D}$ is represented in fig. 12 and 13. In all of them the subsidence behaviour is clear, with deformation velocity from 5 to $7 \mathrm{~mm} /$ year.

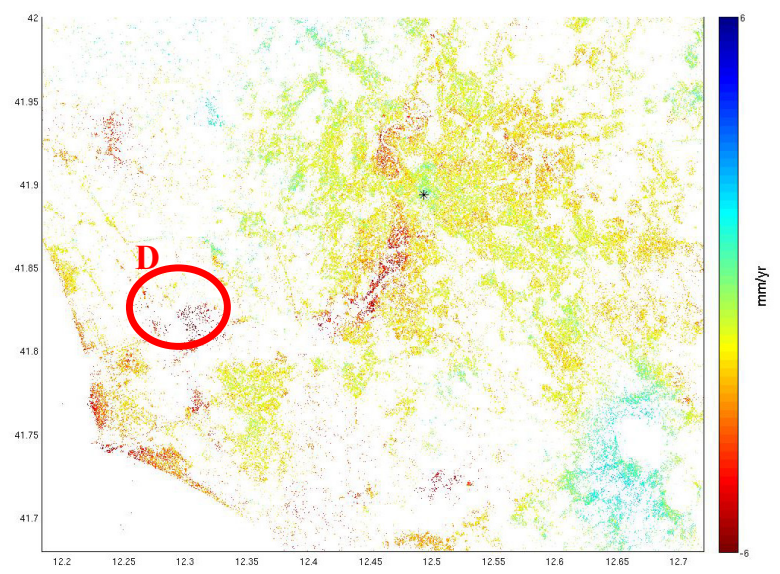

Figure 9. LOS deformation velocities over Rome area obtained with ERS-1/2 SAR descending track 351 from 1992 to 2000. 


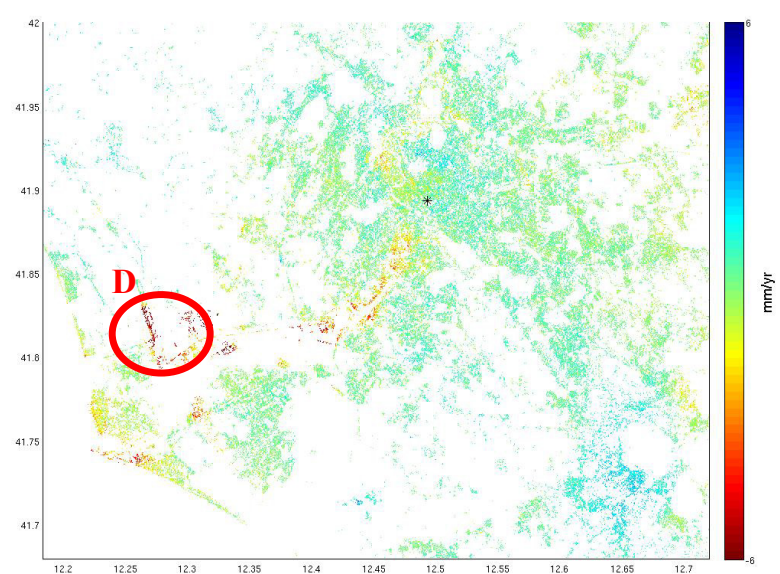

Figure 10. LOS deformation velocities over Rome area obtained with Envisat ASAR track 351 from 2003 to 2010.

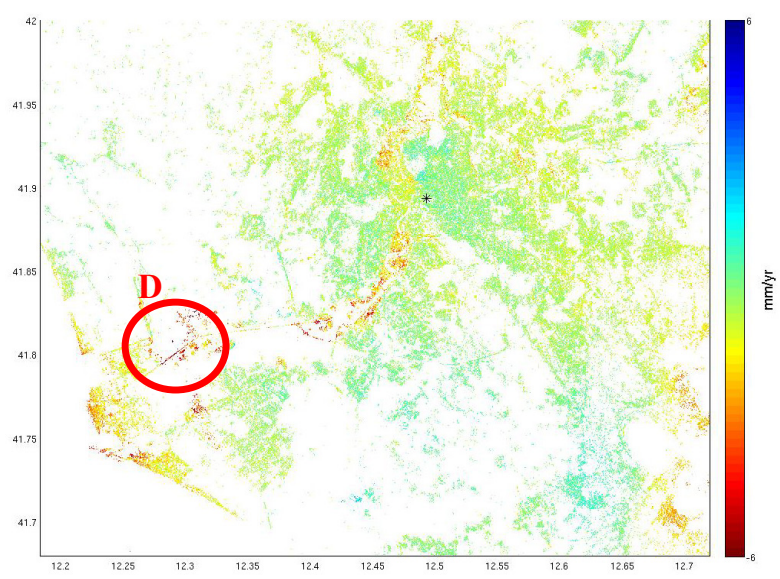

Figure 11. LOS deformation velocities over Rome area obtained with Envisat ASAR ascending track 172 from 2002 to 2010.

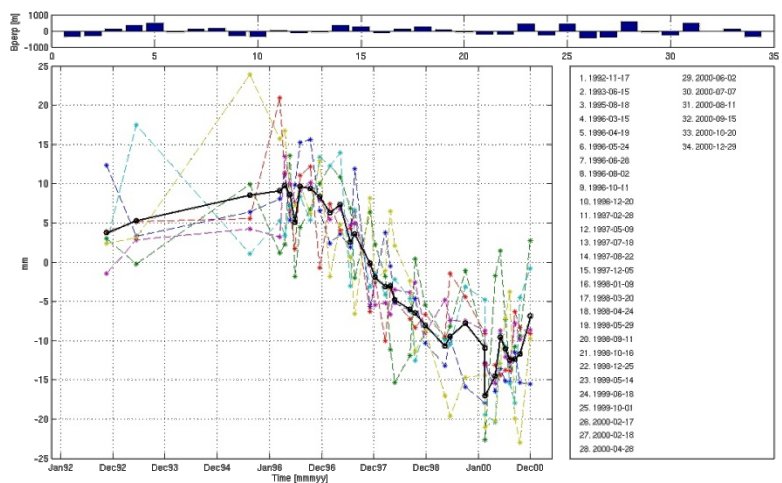

Figure 12. Time series of the Fiumicino area (zone D), showing a subsidence trend from 1992 to 2000.

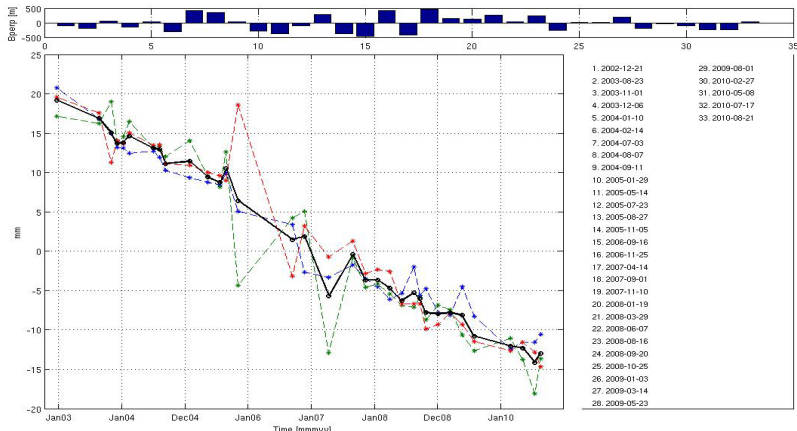

Figure 13. Time series of the Fiumicino area (zone D), showing a subsidence trend from 2003 to 2010. obtained with the ascending track 172.

\subsection{Cagliari}

The interferometric results over Cagliari show that the areas affected by subsidence phenomena are close to the coast (zone E), being the harbour and the area near Sant'Elia football stadium the ones presenting highest subsidence rates of about 5 to $6 \mathrm{~mm} /$ year (fig. 14 and $15)$.

The detailed deformation of a small group of points in zone $\mathrm{E}$ with the highest deformation detected are represented in fig. 16 and 17 for 1995 to 1999 and 2003 to 2010 respectively.

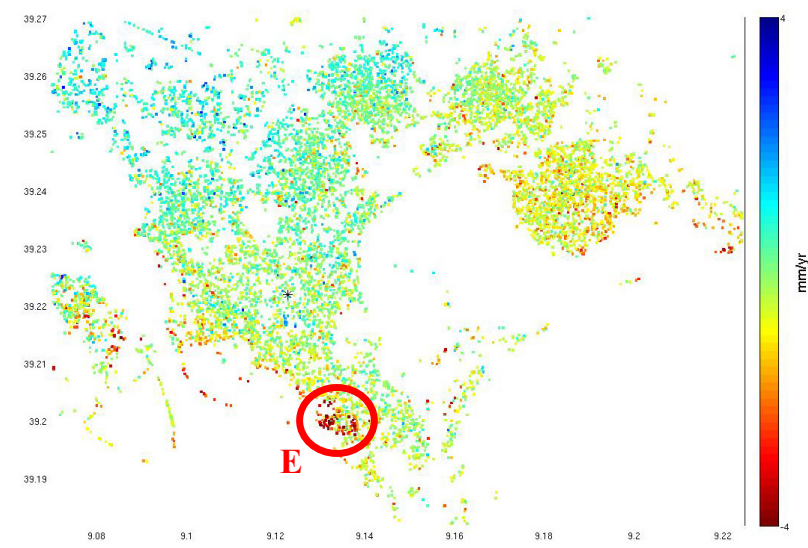

Figure 14. LOS deformation velocities over Cagliari and surroundings obtained with ERS-1/2 SAR descending track 165 from 1995 to 1999. 


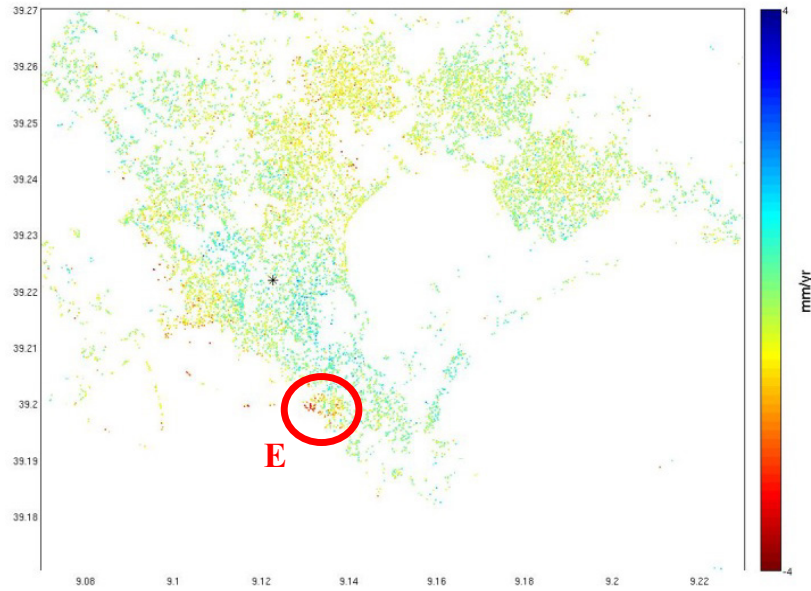

Figure 15. LOS deformation velocities over Cagliari and surroundings obtained with Envisat ASAR descending track 165 from 2003 to 2010.

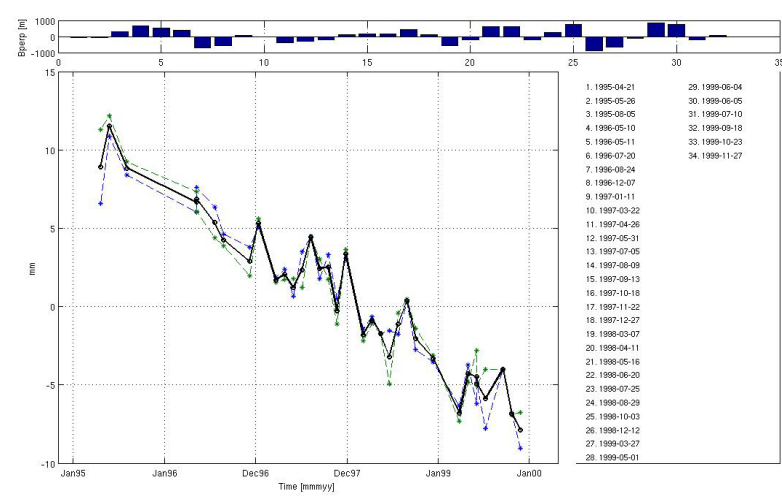

Figure 16. Time series of the football stadium area (zone E), showing a subsidence trend from 1995 to 1999.

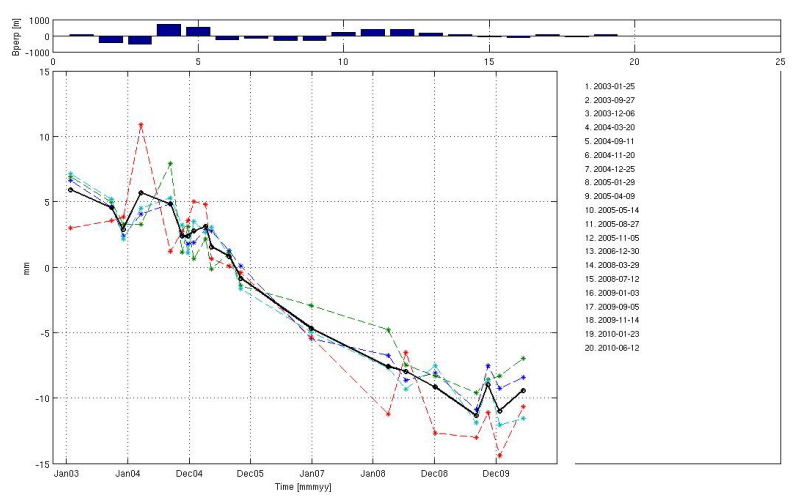

Figure 17. Time series of the football stadium area (zone E), showing a subsidence trend from 2003 to 2010.

\section{CONCLUSIONS}

This work shows the potential of the solutions provided by the ESA Research \& Service Support service (RSS) which make easer the data exploitation allowing users to run the scientific processors close to EO data directly on the ESA Grid and Cloud Computing platforms.
The three areas under study showed evidences of subsidence in rural and public infrastructures.

\subsection{Valencia}

From 1992 to 2010, the harbour shows a continuous subsidence, which decelerates after 1996. In the North East of the city it is also possible to identify an area with lower subsidence rate visible in the whole analysed period. Moreover, outside Valencia city, two different regions present subsidence as well, one from 1992 to 2000 situated to the West of Valencia and the other one detectable only in the period from 2004 to 2010 in the North West with values higher than $5 \mathrm{~mm} / \mathrm{yr}$.

\subsection{Rome}

The entire city area along the Tiber river presents a well-known subsidence (studied already by several authors). Furthermore, Fiumicino airport and surroundings presents significant subsidence, reaching maximum subsidence rates of $7 \mathrm{~mm} / \mathrm{yr}$.

\subsection{Cagliari}

Cagliari shows to be the most stable city among the three analysed in this study, with a subsidence zone near the coast, where the most affected areas are the harbour and the football stadium Sant' Elia.

\section{FUTURE WORK}

Further analysis needs to be carried out to discover the subsidence's causes, and this study is planned to continue by exploiting the interferometric analysis of newer SAR sensors such as Sentinel-1. Higher resolution SAR data could be used with the goal of analysing individual buildings and infrastructures in detail.

\section{ACKNOWLEDGEMENTS}

The authors of this study want to thank ESA RSS service for the interferometric software integrated in their G-POD environments and the powerful CloudToolbox VM made available for the StaMPS processing necessary for this study. We also thank CNR-IREA for the G-POD InSAR P-SBAS service used for the results cross-check. Finally, we want to thank ESA for the data provisioning of ERS-1/2 and Envisat ASAR products and highlight the precision of their orbits.

\section{REFERENCES}

1. Marchetti P.G., Rivolta G., D'Elia S., Farres J., Mason G. and Gobron N. (2012). A Model for the Scientific Exploitation of Earth Observation Missions: The ESA Research and Service Support. IEEE Geoscience and Remote Sensing(162): 10-18 
2. Kampes B., Hanssen R.F. and Perski Z. Radar Interferometry with Public Domain Toolspresentation. Fringe 2003, 1-5 Dec, Frascati, Italy.

3. Hooper, A., Segall, P. \& Zebker, H. (2007). Persistent scatterer InSAR for crustal deformation analysis with application to Volcán Alcedo, Galápagos, J. Geophys. Res. Lett., 112 (B07407), doi:10.1029/2006JB004763.

4. F. Casu, S. Elefante, P. Imperatore, I. Zinno, M. Manunta, C. De Luca and R. Lanari, SBAS-DInSAR Parallel Processing for Deformation Time-Series Computation, IEEE JSTARS, vol. 7, no. 8, pp. 3285-3296, 2014, doi: 10.1109/JSTARS.2014.2322671.

5. Stramondo, S.; Bozzano, F.; Marra, F.; Wegmuller, U.; Cinti, F.R.; Moro, M.; Saroli, M. Subsidence induced by urbanisation in the city of Rome detected by advanced InSAR technique and geotechnical investigations. Remote Sens. Environ. 2008, 112, 3160-3172.

6. Cigna, F.; Lasaponara, R.; Masini, N.; Milillo, P.; Tapete, D. Persistent Scatterer Interferometry Processing of COSMO-SkyMed StripMap HIMAGE Time Series to Depict Deformation of the Historic Centre of Rome, Italy. Remote Sens. 2014, 6, 12593-12618.

7. Delgado, J. M., Cian, F., Ruescas A. B., Sarti, F., Datcu M. and Capilla R., Subsidence Determination in the city of Valencia and its surroundings using radar interferometry, III RAQRS, September 2010, Valencia, Spain.

8. Manunta ,M.M, Loddo, L. F. , Ranieri, R. G. , Lanari, R., On the Exploitation of spaceborne Radar Interferometry for the Earth Surface Deformation Analysis: the Cagliari area case study, II International Conference of Applied Geophysics for Engineering. Messina, Ottobre 1301/2005; 16. 